\title{
Effect of Pressure on Crude-Oil Kinetics During In Situ Combustion
}

\author{
Kuy Hun Koh Yoo,,+ Marta Liliana Trujillo Portillo, "Christian Patiño Ramirez, ${ }^{\S}$ \\ Luiz Eduardo Bittencourt Sampaio, ${ }^{\dagger}$ Margot Gerritsen, ${ }^{\dagger}$ and Anthony R. \\ Kovscek*,† \\ $\dagger$ Department of Energy Resources Engineering, Stanford University \\ $\ddagger$ Currently at Pemex Exploración y Producción \\ IInnovation and Technology Center, Ecopetrol \\ $\S$ Universidad Industrial de Santander \\ E-mail: kovscek@stanford.edu
}

\section{Supporting Information Available}

\section{Data Processing, ICR}

The experimental results from the ICR were post-processed to remove gas analyzer tail effects and to smooth the data. A sum of Gaussians was fit to the experimental data until a good match was achieved around the LTO and HTO regions. Both positive and negative Gaussians were added one by one until a good fit was achieved around the peaks. The fitting was performed using MagicPlot that relies on a Levenberg-Marquardt nonlinear least squares algorithm ${ }^{1}$. Figure 1 shows examples comparing the raw experimental data to the final corrected fit used for the isoconversional analysis. Some of the corrections remove a relatively large area under the oxygen consumption curve, but we are able to justify such 
correction because total oxygen consumption of the corrected curves are consistent with each other.

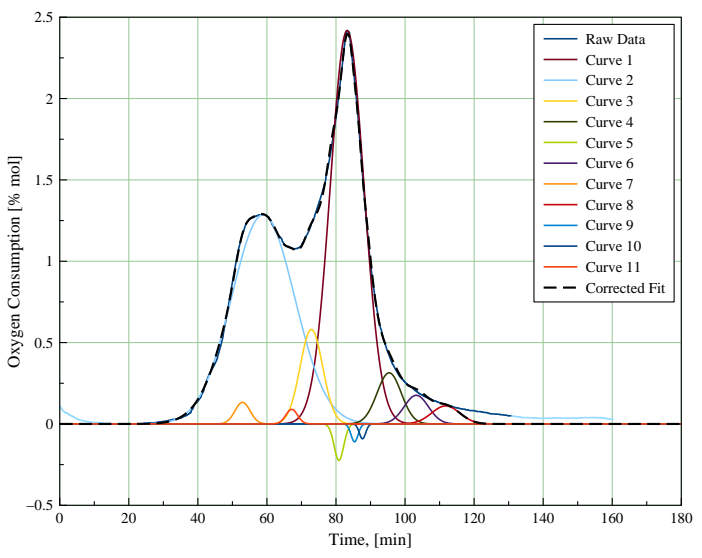

(a) $5.0{ }^{\circ} \mathrm{C} / \mathrm{min}$

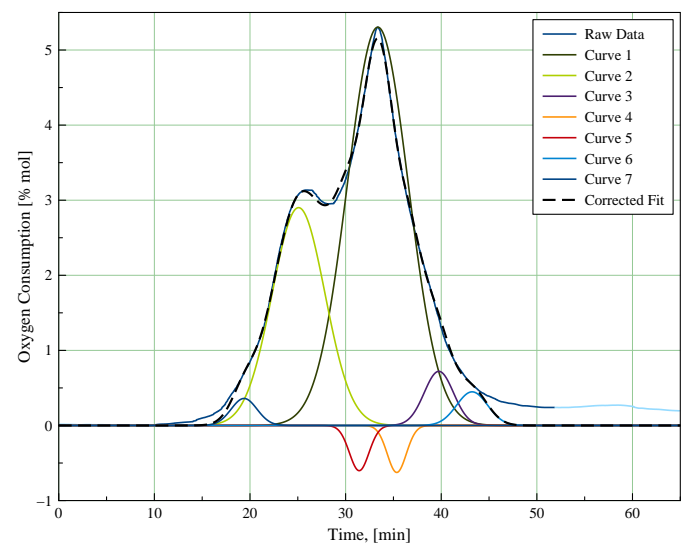

(c) $15.0^{\circ} \mathrm{C} / \mathrm{min}$

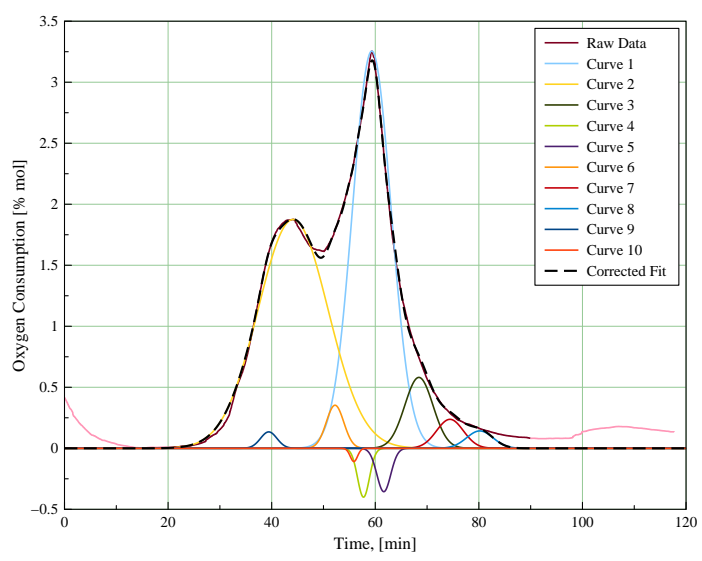

(b) $7.5^{\circ} \mathrm{C} / \mathrm{min}$

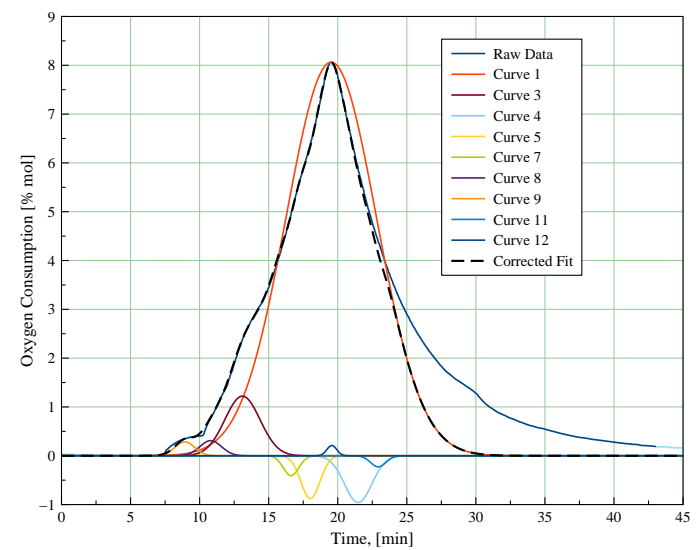

(d) $30.0^{\circ} \mathrm{C} / \mathrm{min}$

Figure 1: Example of using sum of Gaussians to fit different experiments, remove tail effects, and to smooth data. 
Corrections made through Gaussian fitting are similar to corrections made through baseline corrections based on curve rotations as shown in Figure $2^{2}$.

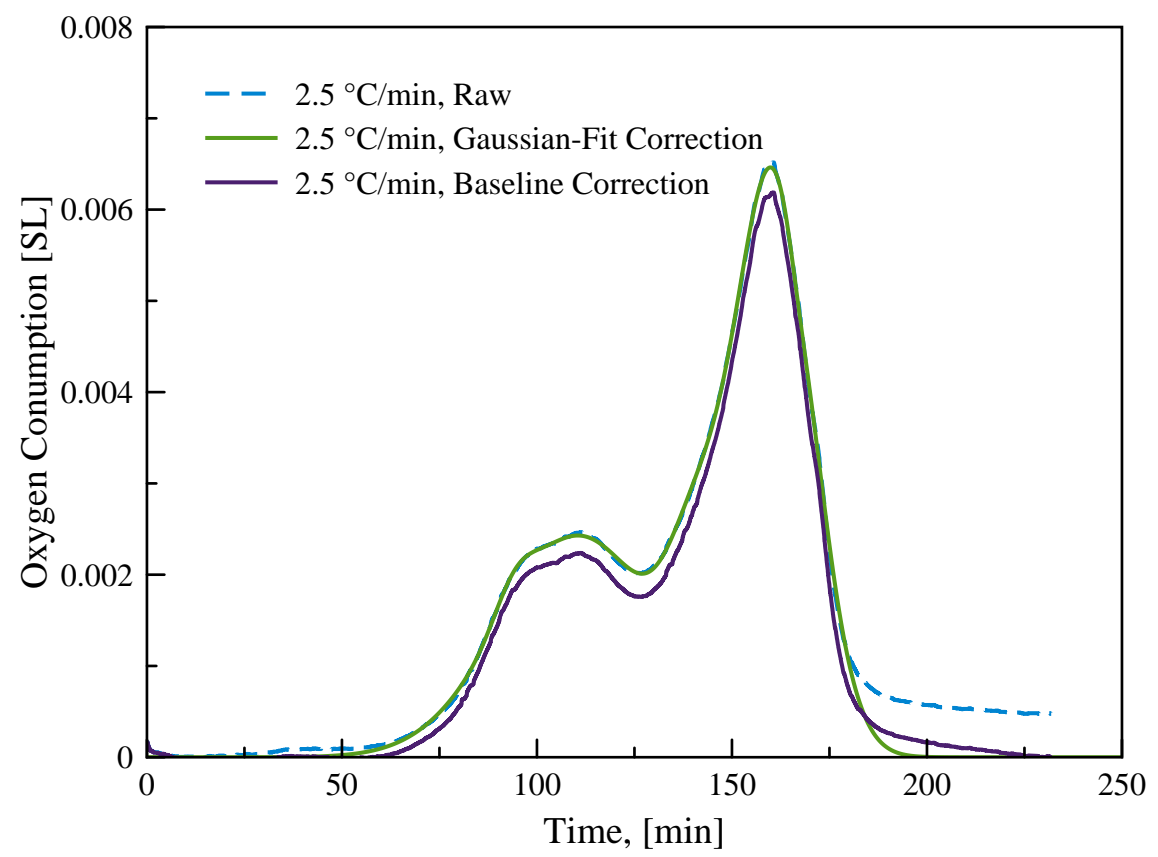

Figure 2: Comparison of experimental data from the ICR post-processed and corrected using Gaussian fits and curve rotation.

\section{Effluent Data from HPFR}

Figures 3 and 4 present available effluent gas results from the high-pressure furnace reactor. 


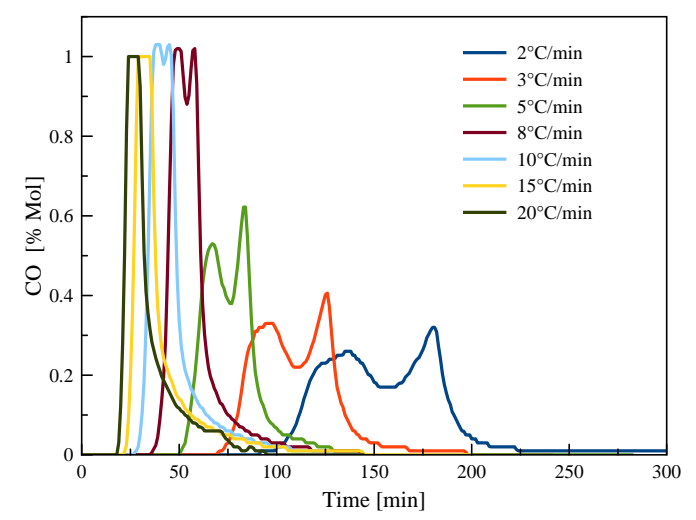

(a) CO Production $400 \mathrm{psi}$

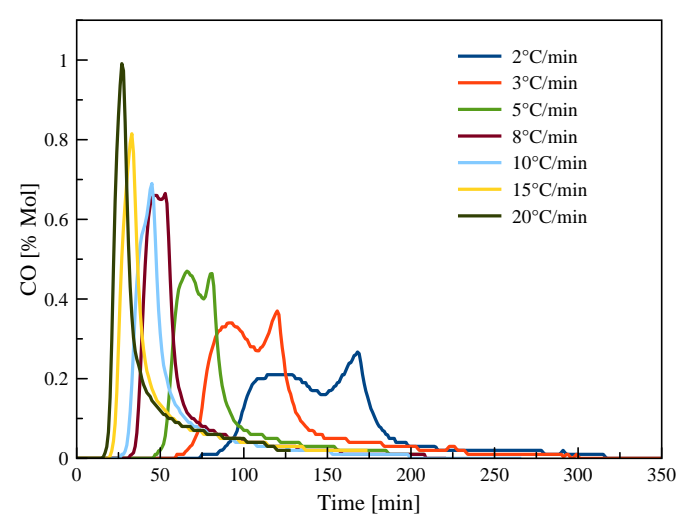

(c) CO Production 1000 psi

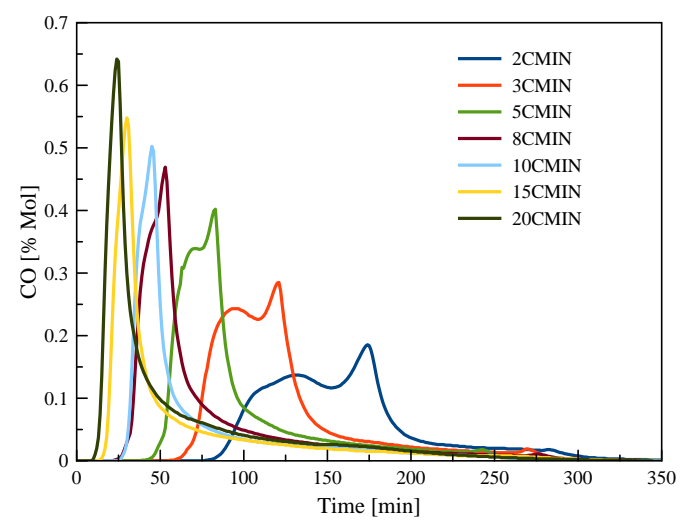

(e) CO Production 1500 psi

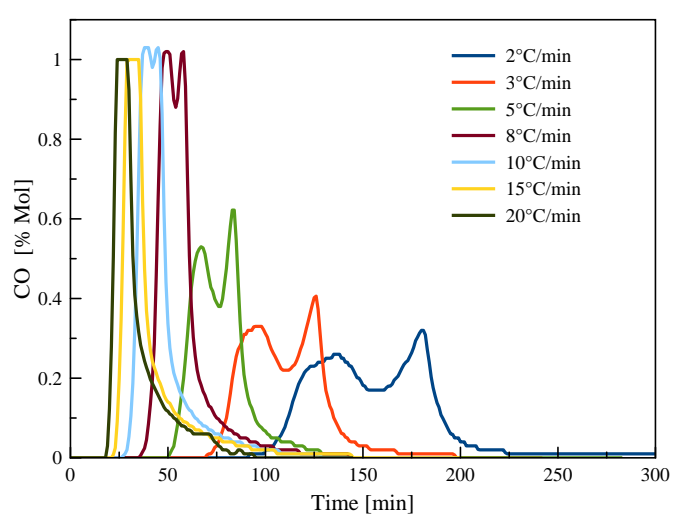

(b) $\mathrm{CO}_{2}$ Production $400 \mathrm{psi}$

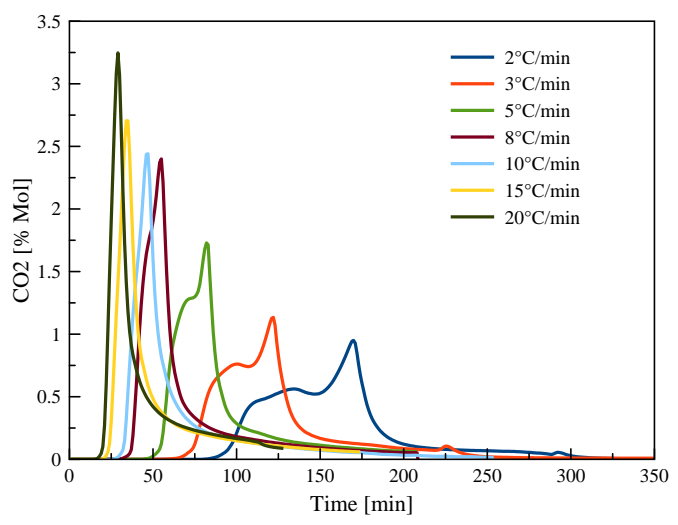

(d) $\mathrm{CO}_{2}$ Production 1000 psi

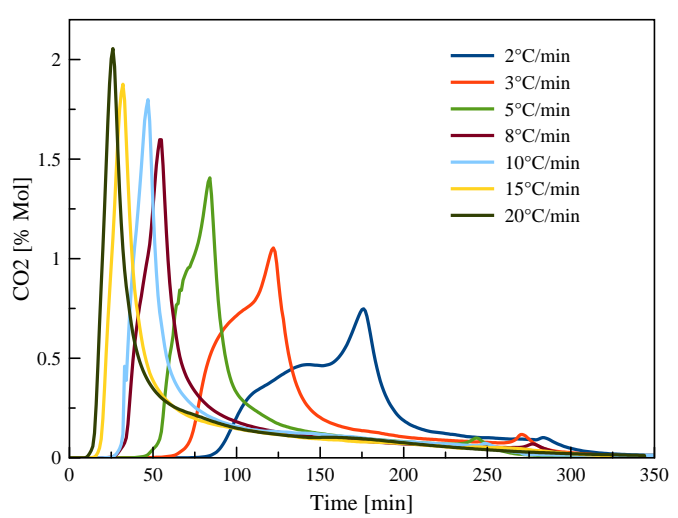

(f) $\mathrm{CO}_{2}$ Production 1500 psi

Figure 3: $\mathrm{CO}$ and $\mathrm{CO}_{2}$ effluent compositions from HPFR experiments. 


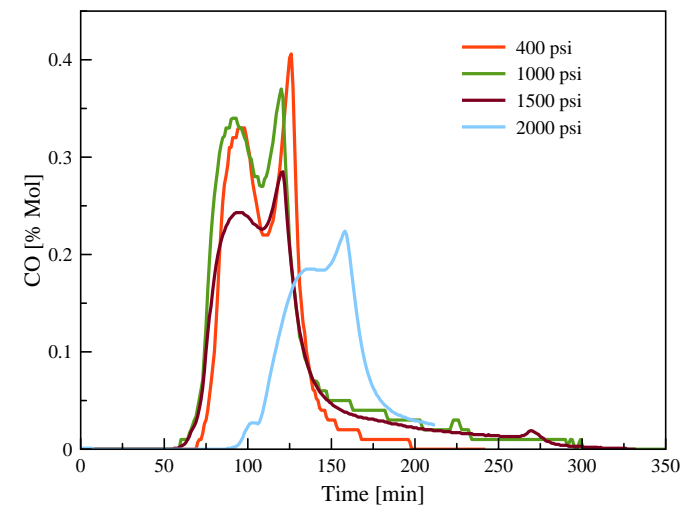

(a) CO Production at different pressures, $3 \frac{{ }^{\circ} \mathrm{C}}{\mathrm{min}}$

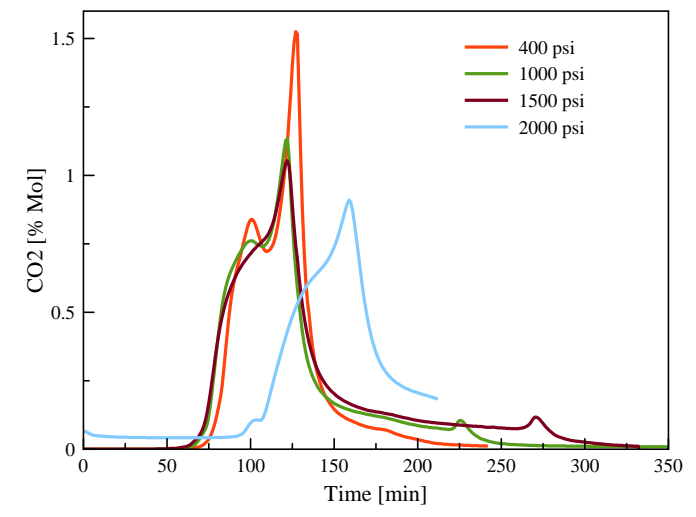

(b) $\mathrm{CO}_{2}$ Production at different pressures, $3 \frac{{ }^{\circ} \mathrm{C}}{\mathrm{min}}$ HPFR

Figure 4: $\mathrm{CO}$ and $\mathrm{CO}_{2}$ effluent compositions from HPFR experiments. 


\section{References}

(1) Motulsky, H.; Christopoulos, A. Fitting models to biological data using linear and nonlinear regression: a practical guide to curve fitting; Oxford University Press, 2004.

(2) Cinar, M. Kinetics of crude-oil combustion in porous media interpreted using isoconversional methods. Ph.D Thesis, Stanford University 2011, 